\title{
Social Video Learning - Creation of a Reflection-Based Course Design in Teacher Education
}

\author{
Eric Tarantini ${ }^{(\bowtie)}(\mathbb{1})$ \\ Institute of Business Education and Educational Management, Digital Learning \\ and Corporate Learning, University of St. Gallen, 9000, St. Gallen, Switzerland \\ eric.tarantini@unisg.ch
}

\begin{abstract}
Reflection on teaching practice is a challenging activity. Often, reflection does only take part on a superficial level. The present contribution describes the creation and first testing of a Social Video Learning (SVL) setting by means of Learning Analytics (LA) for a teacher education course. Furthermore, a theoretical foundation for SVL was tried to create to design the course adequately. Key findings are that (I): SVL has the potential to increase the level of depth in reflection processes, (II): A collaborative and learner centered design is important to benefit from SVL, (III): The use of Learning Analytics in SVL scenarios potentially fosters coaching and learning outcomes of the students.
\end{abstract}

Keywords: Social Video Learning $\cdot$ Learning Analytics $\cdot$ Reflection $\cdot$ Teacher education $\cdot$ Experiential learning

\section{Introduction}

The digital transformation changes our daily business and habits fundamentally [2]. In this light, also the education sector and, consequently, the way of teaching and learning faces significant changes [16]. One medium that comes into play when we talk about digitalization of education is video. Technology-Enhanced Learning (TEL) researchers see the potential in Video-Based Learning (VBL) to be an effective learning method which can replace or enhance traditional classroom-based and teacher-led learning approaches [4]. So called "Social Video Learning" (SVL) is a method inspired by the idea of using video annotation in a collaborative setting. Thereby, video-annotation (enrichment with comments and visual elements) is used to enable situational reflection processes [14, 26]. Prior research shows first encouraging results, that an interactive use of video content enhances student motivation and engagement [17]. However, there is still a lack of knowledge on whether the use of video in instructional settings represents an effective way to foster learning. First results in the context of SVL seem promising [24]. Furthermore, Learning Analytics (LA) offers the possibility to facilitate learning and to evaluate learning progress with SVL [21].

The aim of this paper is to create a theoretically founded learner-centered course design. The questions to be discussed in this paper are the following ones: 1. How can 
SVL be theoretically founded to create an effective learning design? 2. How can a SVL setting in combination with LA for a teacher education course be designed?

The paper is structured as follows: the first section focusses on the rationale of the research project: 1) what are the benefits of social video learning 2) why is social video learning a suitable tool to foster effective learning and reflection; in the second section, the applied research methodology will be explained; the third section sums up the relevant findings of my study.

\section{Rationale of the Research Project}

What are Benefits of SVL? SVL intends and enables active work with video materials. Specifically, the core of the video-analytical work with SVL lies in the platformbased video annotation. On the platform (we use the edubreak CAMPUS platform; edubreak.de), learners actively watch and work with videos [15, 18, 26]. Comments and visual markings, accurate to the second within the video player, enable reflection in and about the specific situation. Through these annotations, the learner is asked to visually specify the reference point for his interpretation and to formulate it in an understandable way for third parties [4, 27]. Explaining one's own thoughts, experiences, or insights within the learning process thus ensures a sustainable learning progress. The didactical relevance of this procedure can be enhanced by linking video situations to concrete observation assignments - these help to explicate subjective thinking in the video in a targeted manner $[26,27]$. Towards a commentary-based interpretation, one's mental model becomes visible and perceptible within the framework of SVL. Thus, a "goal-oriented reflection" is the consequence to expand the personal spectrum of action and bring about changes in teaching practice $[9,24]$.

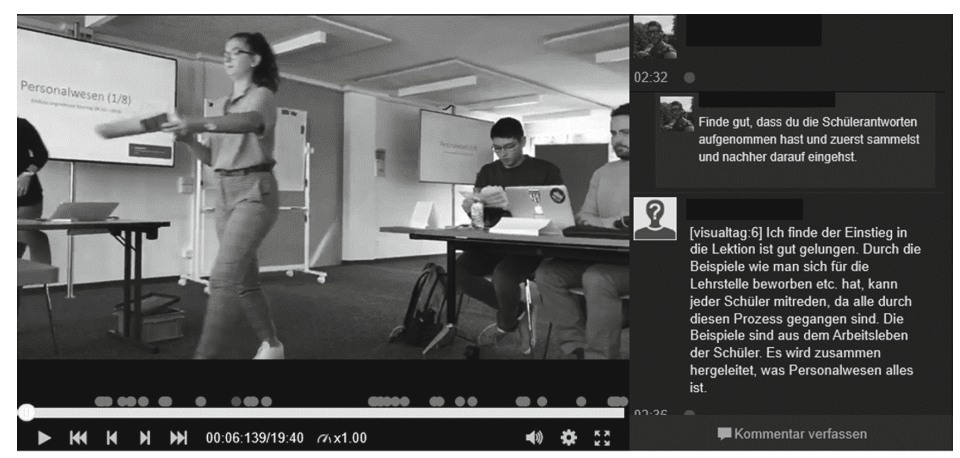

Fig. 1. Social video learning on the edubreak CAMPUS platform (edubreak Player).

Why do We Use SVL in Teacher Education? The integration of reflection processes in teacher education is an essential success factor for the development of students' teaching skills $[14,24]$. In addition to written and oral feedback, teaching units from students are recorded in the microteaching (core course for the development of teaching 
skills in law and economics for high schools and VET schools at the University of St. Gallen). The independent video watching and reflection of learners represented the lived practice in the original course design. However, there is evidence that knowledge is developed more effectively in groups than individually [4, 25]. The verbalization and explication of observations within reflection processes has a positive effect on teachers' work related to their own "technical language" [26]. From a lecturers' perspective, video annotation represents a very clear documentation of the learning process within the teacher education course. This supports coaching processes and enables the use of LA, which will be explained in the next sections.

\section{Theoretical Base and Method}

This section describes the theory building, the methodological approach and how LA is implemented in the project.

\subsection{Theoretical Framework and Adaptation to Course Setting}

The creation of an effective learning process (i.e. fully understanding something) is linked to real life experience combined with reflection and abstraction. To create an adequate theoretical framework for SVL I worked with Kolbs' "experiential learning theory" [12]. Kolb stresses the crucial role of practical experience for learning processes [13]. Furthermore, experiential learning is based on the foundation of interdisciplinary and constructivist learning $[1,20]$. The core principle is that "learning is a process in which knowledge is created through the transformation of experience. Knowledge therefore results from a combination of the acquisition and transformation of experience" [13]. Experiential learning can take place both field- and classroom-based [20]. According to Kolb and Fry [12] experience-based learning happens cyclically. The steps of this process have been transferred to the microteaching course (Fig. 2).

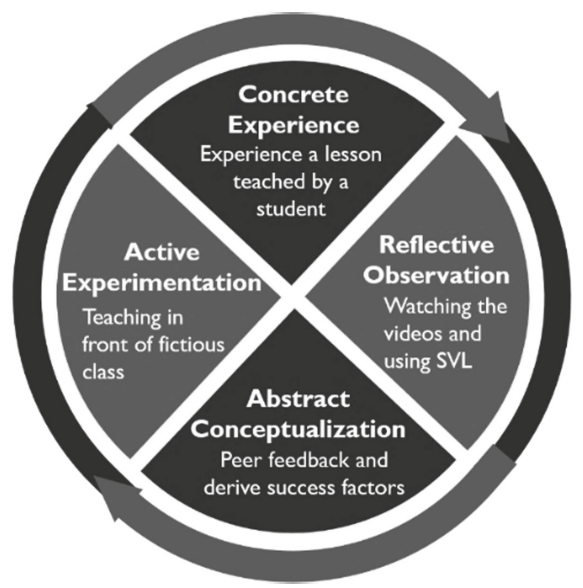

Fig. 2. Cyclical experiential learning. Own illustration adapted from Kolb [12]. 
The starting point is a concrete, observed or personally made experience. The students observe a teaching unit of a colleague (concrete experience). Subsequently, the video sequence is uploaded on the platform to be annotated and reflected (reflective observation). The concrete observation is used to derive general principles of action for the individual teaching practice through a personal coaching (abstract conceptualization). Finally, one's teaching activity is carried out, which is to be optimized with the help of the preceding processes and the start of a new cyclical learning process (active experimentation). As a whole, continuous reflection enables effective learning [19].

\subsection{Course Characteristics and Research Method}

The microteachings take place every autumn semester on Bachelors' Level. The students plan a teaching unit in detail (45 min). From this unit, a microteaching sequence (20 min) will be carried out in front of the fellow students (fictious class). The course is split up in two rounds of microteachings, i.e. every student teaches twice a semester. The first round takes place in the first six weeks of the semester, the second round after a break of two weeks in the following six weeks. This structure allows to gather data within the first round, to analyze it by means of LA and consequently improve performance aspects of the students within the second round (Fig. 3).

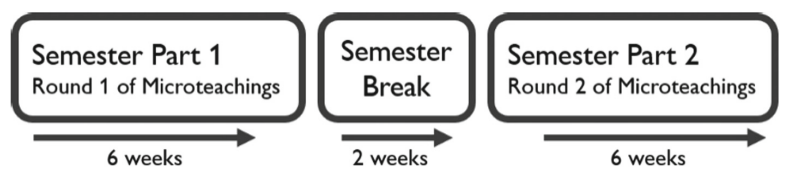

Fig. 3. Semester structure. Own illustration.

The course was set up by means of Blended Learning. The combination of face-toface and online-learning in a Blended Learning Design allows to effectively promote teaching skills in a team because video annotations can be discussed, clarified and reflected within the classroom setting $[6,24]$. The special thing about the course design was, that the SVL part (online) was integrated in the weekly presence setting of four lessons (six times per semester). The students reacted positively to the combination of online feedback through annotations and oral feedback right afterwards. However, it must be emphasized that a detailed evaluation of the established course design is not part of this paper.

\subsection{Learning Analytics to Enhance SVL}

This section describes an approach of how the learning processes in teacher education can be supported by means of LA in order to optimize coaching/feedback processes and consequently achieve higher learning outcomes.

What Benefits Can Result from Learning Analytics? The main purpose of LA lies in the development of methods that harness educational data sets to support a specific learning process. While much of the interest in Big Data and LA is currently focused on 
prediction, reflection (i.e., monitoring and understanding) may in fact become more widely relevant $[7,8,21,23]$. Especially, as learners take on more responsibility in managing their individual learning processes. Moreover, it is highly challenging to provide personal feedback to a big number of learners in a video-based learning setting [4]. Therefore, effective methods that enable to track learners' activities and extract conclusions about the learning process in order to support personalized and networked VBL are needed. Chatti et al. [4] state, LA "can play a crucial role in supporting an effective VBL experience. LA that focuses on the perspectives of learners can help to create the basis for effective personalized VBL, through the support of monitoring, awareness, self-reflection, motivation, and feedback processes". I regard these findings as important for SVL settings as they can be interpreted as a form of "networked VBL". To sum up, the core idea is to evaluate the gathered data from a learning process in order to support learners more effectively [8, 22].

What Data is Collected and How is it Collected? In the described course setting, data is produced by the students themselves as they annotate microteaching videos of their colleagues within the SVL-process. These annotations are illustrated in the following figure as data points on the timeline of the video player. Each data point stands for one annotation (consisting of the point and a text comment linked to it; see also Fig. 1) (Fig. 4).

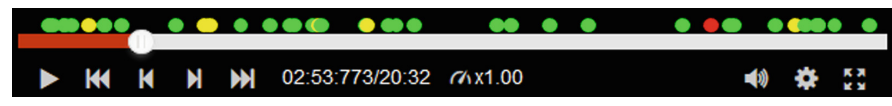

Fig. 4. Social video learning player with annotations (edubreak CAMPUS platform).

On the edubreak CAMPUS platform, annotations can be classified with green, yellow or red colors. Depending on the setting, the coding of the annotations can be individualized (e.g. red for critical situations, yellow for discussable and green for successful or positive situations). The annotations are then analyzed in detail with the students. The result is a detailed feedback from the peers and from the lecturer. Furthermore, potential improvements for future teaching can be pointed out very clearly. As we go through two rounds of microteachings, students have the possibility to optimize their performance through SVL and LA.

How can LA be Structurally Designed in a Learning Setting? Seufert et al. [21] provided a design framework for LA in teaching settings. It comprises four different procedural steps to be considered. The implications are transferred as well to the microteaching course (Fig. 5): 


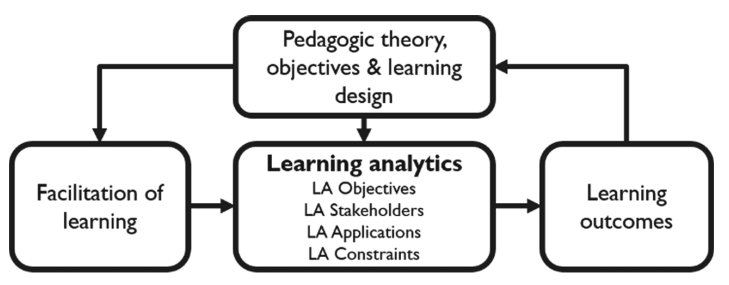

Fig. 5. LA design framework. Own illustration adapted from Seufert et al. [21].

Pedagogic Theory and Learning Design. The base in this paper is a socioconstructivist understanding of learning (experiential learning theory by Kolb, 1975). It is therefore hypothesized, that students' learning outcomes are enhanced by discussing in groups and, consequently, working with SVL.

Objective. For the described course design, the main objective is to enhance teaching competences through effective learning and reflection. Analyzing teaching performance by the use of SVL and LA represents the base for the overall reflection [8].

LA objectives. Greller and Drachsler [10] mainly distinguish between "reflection" and "prediction"as LA objectives. However, "individual learning" and/or "social learning" need to be differentiated as well. Especially from a pedagogical perspective the distinction between social and individual learning is important [22]. SVL can be classified as social-reflective as students actively work with and discuss on video content within their group. Social learning analytics for reflection imply a shift in attention away from summative assessment of individuals towards learning analytics of social activity [3].

LA Stakeholders. Stakeholders in LA activities are those that either are subjects of data analysis services or clients of data analysis services. In the SVL setting, students are clients of data analyses in that specific analyses aim at enhancing their teaching competences.

LA Application. The LA application can be represented by technologies, platforms, data sets, and algorithms employed in carrying out analytics activities [10]. In the SVL setting the edubreak CAMPUS platform for video annotation was used.

LA Constraints. Rules and regulations concerning privacy and ownership of data, ethical considerations, as well as cultural norms and values are possible constraints [8]. For SVL, questions of data ownership arise as reflection takes part in groups on reallife teaching experiences of the students in the course.

However, further research should be conducted to challenge this first approach of designing a course by means of experiential learning and LA.

\section{Results and Discussion}

In this section, the main outcome of this paper, i.e., the Blended Learning Design of the teacher education course is described. 


\subsection{Blended Learning Design}

Why is a Blended Learning Design Used to Implement SVL? First of all, the course design was constructed with four main steps, which are described in detail as follows. The model was established and discussed with lecturers from the university of St. Gallen. In 2019, a group of eleven students tested the new course design for the first time (Fig. 6).

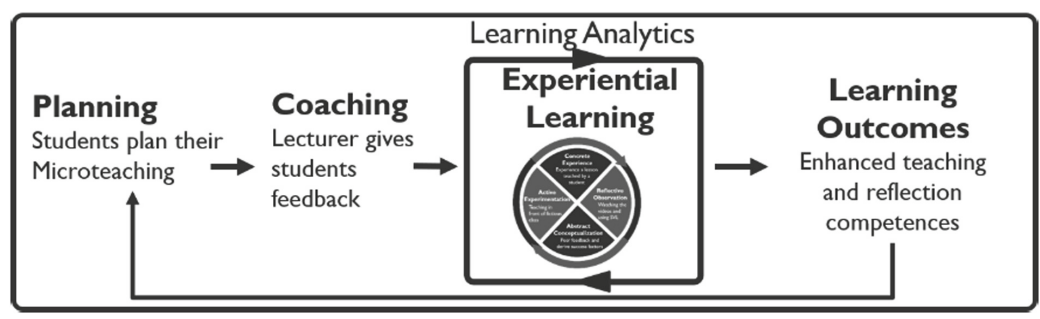

Fig. 6. Blended learning design for teacher education course. Own illustration.

Planning. At the start of the semester, students (teachers in training) prepare themselves in self-study for their teaching unit in business administration, economics, law or accounting (for the context of a high school or vocational school). The lesson planning includes detailed information about the general conditions, learning objectives, disposition as well as the working materials used within the lesson. Thereby, the students gain a deeper understanding of the complexity of teaching. The planning of the microteaching takes place during the first three weeks of the semester.

Coaching. In the coaching session, students receive constructive feedback on their lesson planning from the lecturer. This facilitates their learning process, as they get to know very concretely, where to improve. The lesson planning is critically examined, discussed and adapted with regard to the actual implementation. This discussion between student and lecturer is also intended to enable didactic decisions within the planning to be justified and ultimately implemented.

Experiential Learning. The four steps derived from Kolbs' experiential learning theory represent the core process of the presence setting (see Sect. 4.1). The microteachings take place in front of the fellow students as well as the lecturer and are recorded via smartphone (active experimentation). After the microteaching, students provide feedback first via SVL and orally right afterwards. This allows them to improve their oral feedback competence by gaining a higher sensitivity for critical situations in teaching by using SVL. The addition and implementation of the following elements were meant to enhance learning outcomes of the students. The first impressions are promising:

Social Video Learning Supported by Application-Based Live Annotation. As the lecturer starts the "live video"-function within the edubreak App, students have the possibility to annotate via their mobile phone during a lesson held by one of their 
fellow students (see Fig. 7). The observing students can add time stamps (so-called "tags") via the application already during the teaching in order to "save" important situations (concrete experience). The edubreak App allows the lecturer to directly upload the video on the edubreak CAMPUS. This saves time and allows consequently to focus on the formulation of the text comments within the edubreak Player (see Fig. 1) (reflective observation). The interpretation of those data points by means of LA happens after the microteachings. The lecturer analyzes the annotations from the students, and identifies optimization potentials within the observed criterions for the microteachings (e.g. media use, interaction with learners, body language etc.). Furthermore, the platform-based video annotation sequence is followed up by a face-toface feedback session in order to reflect further and to enhance the cyclical experiential learning procedure. This analysis sets the base for the next coaching sessions with the students before the second round of microteachings.

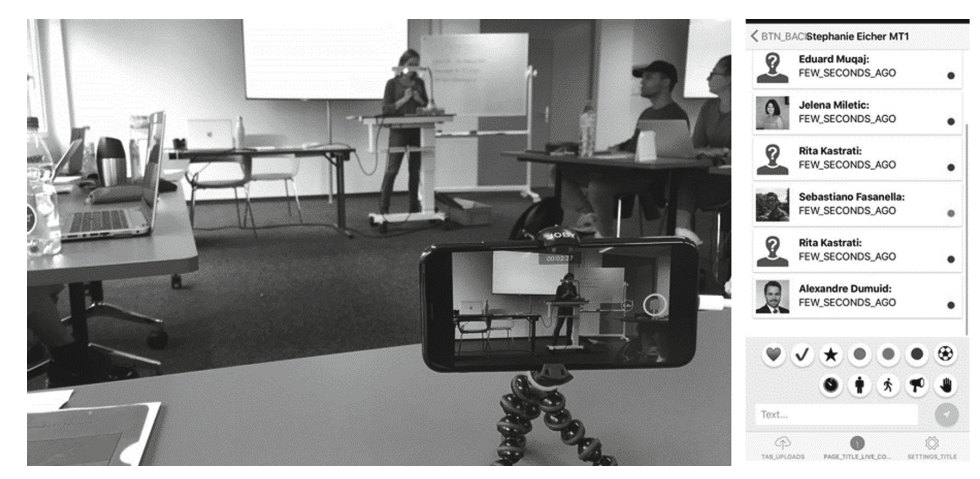

Fig. 7. Live-video in the microteaching and user interface on the edubreak App.

Allocation of Observation Criteria to Enhance Reflection Focus. To assure substantial and concrete feedback, students (fictious class) are asked to observe one specific criterion during the teaching unit (e.g. use of media, teacher behavior, etc.) (abstract conceptualization). This creates a sense of responsibility during the observation, annotation and face-to-face feedback session. Furthermore, LA can be used based on the specific criteria to measure students' progress.

Learning Outcomes. Based on the inputs via SVL, the oral feedback (face-to-face) and the personal impressions, a short reflection report (approx. 6 pages) is written. The students identify their major optimization potentials and describe alternative teaching behaviors. This process is supported and facilitated by SVL.

\section{Conclusion and Limitations}

In conclusion, first impressions are that SVL has the potential to improve teaching competences. It supports group-based reflection processes and allows collaborative and active work with video materials. Moreover, LA can play an important role to enhance 
learning outcomes. The allocation of focus criteria for the observation of microteachings showed positive effects. This steering element allowed the definition of clear responsibilities for the annotation work on the SVL platform within the classroom session and with regard to the subsequent oral feedback round. Despite the technological innovation, social aspects like communication, empathy and trust turned out to be crucial elements in order to establish a respectful group- and, in consequence, feedback-culture [5]. Compared to previous course designs, SVL helped students to develop a certain "situational sensitivity" $[24,26]$. However, those effects have to be evaluated and verified in detail. But first impressions show, that the students' ability to reflect in depth on specific situations tend to improve from the first to the second round of microteachings.

However, there are some limitations to this research. First of all, the course was carried out with a relatively small group of eleven students at university level. Further studies should therefore focus on creating effective course designs for larger groups and on different school levels. During the course, the trustful and open group culture turned out to be the core factor. In addition, the development of an honest, appreciative and respectful feedback culture within the group may have a direct effect on the quality of SVL. The quality of feedback is essentially determined by the established, familiar level of relationships within the group, an effect also known as "psychological safety" $[5,11]$. Moreover, as this paper illustrates a first approach to combine SVL with LA, results have to be critically examined and analyzed to validate the course design. It has to be stressed, that this paper is about the modelling approach of such a setting and not about the evaluation.

Future work should consist in the creation, testing and evaluation of other SVLbased education settings. First indications are that the technology brings new and interesting perspectives for reflection in teacher education. Furthermore, it would be interesting to test whether the technology can be used with added value on other educational stages (e.g. high school).

\section{References}

1. Bada, S.: Constructivism learning theory. A paradigm for teaching and learning. IOSR J. Res. Method Educ. (IOSR-JRME) 5, 66-70 (2015)

2. Brynjolfsson, E., McAfee, A.: The Second Machine Age: Work, Progress, and Prosperity in a Time of Brilliant Technologies. Norton, New York (2014)

3. Buckingham Shum, S., Deakin Crick, R.: Learning dispositions and transferable competencies: Pedagogy, modelling and learning analytics. In: Proceedings 2nd international Conference on Learning Analytics and Knowledge, pp. 324-335. ACM Press, New York (2012)

4. Chatti, M.A., Marinov, M., Sabov, O., Laksono, R., Sofyan, Z., Yousef, A., Schroeder, U.: Video annotation and analytics in course mapper. Smart Learn. Environ. 3, 10 (2016)

5. Edmondson, A.: Psychological Safety and Behavior in Work Teams. Harvard University, Cambridge (1999) 
6. Ganz, A., Reinmann, G.: Blended Learning in der Lehrerfortbildung. Evaluation einer Fortbildungsinitiative zum Einsatz digitaler Medien im Fachunterricht. Unterrichtswissenschaft 35(2), 169-191 (2007)

7. Gaviria, F., Glahn, C., Drachsler, H., Specht, M., Gesa, R.F.: Activity-based learner-models for learner monitoring and recommendations in Moodle. In: Kloos, C.D., et al. (eds.) Proceedings of the 6th European Conference on Technology-Enhanced Learning, pp. 111124. Springer, Heidelberg (2011)

8. Gedrimiene, E., Silvola, A., Pursiainen, J., Rusanen, J., Muukkonen, H.: Learning analytics in education: literature review and case examples from vocational education. Scandin. J. Educ. Res. (2019). https://doi.org/10.1080/00313831.2019.1649718

9. Greif, S.: Coaching und ergebnisorientierte Selbstreflexion. Hagrefe Verlag, Göttingen (2008)

10. Greller, W., Drachsler, H.: Translating learning into numbers: a generic framework for learning analytics. Educ. Technol. Soc. 15(3), 42-57 (2012)

11. Hilzensauer, W.: Videoreflexion 2.0. Zur Rekonstruktion subjektiver Theorien über guten Unterricht. Medienimpulse - Beiträge zur Medienpädagogik (2012) Ausgabe 03 (2010). http://www.medienimpulse.at/articles/view/446

12. Kolb, D.: Experiential Learning: Experience as the Source of Learning and Development. Prentice-Hall, Englewood Cliffs (1984)

13. Kolb, D.A., Boyatzis, R., Mainemelis, C.: Experiential Learning Theory. Previous Research and New Directions. Case Western Reserve University, Cleveland (1999)

14. Krammer, K., Reusser, K.: Unterrichtsvideos als Medium der Aus-und Weiterbildung von Lehrpersonen. Beiträge zur Lehrerbildung 23(1), 35-50 (2005)

15. Krüger, M., Steffen, R. Vohle, F.: Videos in der Lehre durch Annotation reflektieren und aktiv diskutieren. In: Csanyi, G., Reichl, F., Steiner, A. (eds.) Digitale Medien - Werkzeuge für exzellente Forschung und Lehre, pp. 198-210. Waxmann Verlag GmbH, Münster (2012)

16. Kumar, B.S., Nivedhitha, D., Chitra Mai, M.R., Perumal, A.: Digital tools for effective learning. Int. Res. J. Eng. Technol. (IRJET) 3, 381-384 (2016)

17. Lee, C., Tsai, C.: An efficient approach to slicing learning video to improve learning effectiveness by considering learner prior knowledge. National University of Taiwan, Taiwan (2018)

18. Meixner, B., Siegel, B., Hölbling, G., Kosch, H., Lehner, F.: SIVA suite - konzeption eines frameworks zur erstellung von interaktiven videos. In: Eibl, M. (ed.) Workshop Audiovisuelle Medien WAM 2009. Aus der Reihe Chemnitzer Informatik-Berichte, pp. 13-20. Technische Universität, Chemnitz (2009)

19. Passarelli, A., Kolb, D.: Using experiential learning theory to promote student learning and development in programs of education abroad. Case Western Reserve University, Cleveland (2011)

20. Schwartz, M.: Best Practices in Experiential Learning. Ryerson University (2012)

21. Seufert, S., Meier, C., Soellner, M., Rietsche, R.: A Pedagogical Perspective on big data and learning analytics. A conceptual model for digital learning support. Universität St.Gallen: Institut für Wirtschaftspädagogik (2019a)

22. Seufert, S., Guggemos, J., Sonderegger, S.: Digital transformation in higher education: augmentation strategies for the use of data analytics and artificial intelligence (AI). ZFHE 15 (1), 81-101 (2019b)

23. Siemens, G., Gasevic, D., Haythornthwaite, C., Dawson, S., Shum, S. B., Ferguson, R., et al.: Open learning analytics: an integrated \& modularized platform, 28 July 2011 
24. Tarantini, E.: Social Video Learning Projekt im Didaktischen Transfer der Zusatzausbildung Wirtschaftspädgogik. Planung, Durchführung und Evaluation eines neuen Kursdesigns. Masterarbeit. Universität St.Gallen: Institut für Wirtschaftspädagogik (IWP-HSG) (2016)

25. Trendreport: Vernetzte Gesellschaft. Der Trend hin zur Digitalisierung in der Wirtschaft und Gesellschaft ist ungebrochen. Eine stille Evolution, die Märkte und Macher treibt. In: Handelsblatt (2015). http://trendreport.de/category/ausgaben/032015/. Accessed 28 Oktober

26. Vohle, F., Reinmann, G.: Förderung professioneller Unterrichtskompetenz mit digitalen Medien: Lehren lernen durch Videoannotation. In: Schulz-Zander, R., Eickelmann, B., Moser, H. Niesyto, H., Grell, P. (eds.) Jahrbuch Medienpädagogik, vol. 9, pp. 413-429. Springer, Wiesbaden (2012)

27. Vohle, F.: Lernen 5.0. Fünf Innovationsdimensionen für eine veränderte Lehr-, Lern- und Prüfungskultur mit Social Video Learning. Vortrag SCIL Webinar, 16 October 2019 (2019) 